\title{
Proteomics analysis of siRNA-mediated silencing of Wilms' tumor 1 in the MDA-MB-468 breast cancer cell line
}

\author{
MUSLEEHA CHESOR ${ }^{1}$, SITTIRUK ROYTRAKUL ${ }^{3}$, \\ POTCHANAPOND GRAIDIST $^{2}$ and KANYANATT KANOKWIROON ${ }^{2}$
}

\begin{abstract}
${ }^{1}$ Programme of Biomedical Sciences, Department of Biomedical Sciences, Faculty of Medicine, Prince of Songkla University, Hat Yai, Songkhla 90110; ${ }^{2}$ Department of Biomedical Sciences, Faculty of Medicine, Prince of Songkla University, Hat Yai, Songkhla 90110; ${ }^{3}$ National Center for Genetic Engineering and Biotechnology, National Science and Technology Development Agency, Pathumthani 12120, Thailand
\end{abstract}

Received November 15, 2013; Accepted December 30, 2013

DOI: $10.3892 /$ or.2014.3013

\begin{abstract}
The Wilms' tumor 1 (WTI) gene encodes a zinc finger which appears to be a transcriptional activator or repressor for many genes involved in cell differentiation, growth and apoptosis. In order to determine the relationship between WT1 and related proteins, WT1 was silenced with small interfering RNA (siRNA) and the protein expression pattern was analyzed by proteomics analysis including one-dimensional gel electrophoresis (1-DE) and LC-MS/MS mass spectrometry. The results revealed that 14 proteins were expressed in WT1-silenced cells ( $\left(\mathrm{siRNA}_{\mathrm{WT1}}\right)$ and 12 proteins were expressed in the WT1-expressing cells (siRNA ${ }_{\text {neg }}$ ), respectively. These proteins may be classified by their functions in apoptosis, cell signaling, protein folding, gene expression, redox-regulation, transport, structural and unknown functions. Mitogaligin, an apoptosis-related molecule, was identified when WT1 was silenced while the proteins related to the signaling pathway were detected in both siRNA ${ }_{\text {neg }}$ and siRNA $\mathrm{wT}_{\mathrm{WT}}$ but the type of proteins were different. For example, the IBtK protein and the $\mathrm{SH} 2$ domain-containing protein were present in siRNA $_{\mathrm{WT} 1}$ conditions, while the platelet-derived growth factor receptor $\alpha$ (PDGFRA) and Rho guanine nucleotide exchange factor 1 (Rho-GEF 1) were expressed in siRNA ${ }_{\text {neg }}$. Of these, Rho-GEF was selected for validation by western blot analysis and demonstrated to be present only in the presence of WT1. In conclusion, WT1 is related to mitogaligin via EGFR and behaves as an anti-apoptotic molecule. Moreover, WT1 may be associated with PDGFRA and Rho-GEF 1 that activates proliferation in MDA-MB-468 cells.
\end{abstract}

Correspondence to: Dr Kanyanatt Kanokwiroon, Department of Biomedical Sciences, Faculty of Medicine, Prince of Songkla University, Hat Yai, Songkhla 90110, Thailand

E-mail:kkanyana@medicine.psu.ac.th; topten08@hotmail.com

Key words: proteomics, Wilms' tumor 1, siRNA, mitogaligin, platelet-derived growth factor receptor $\alpha$, Rho guanine nucleotide exchange factor 1

\section{Introduction}

Breast cancer is the most common cancer and the leading cause of mortality in women worldwide, accounting for $23 \%$ (1.38 million cases) of the total new cancer cases and $14 \%$ (458,400 cases) of all cancer deaths in 2008 (1). The development of breast cancer may result from interaction between the change in genetic elements, environmental factors and also the difference in ethnicity (2). There are several genes reported to be associated with breast cancer, such as $E R B B 2, c-M y c$, CCNDI, TP53, PTEN and Wilms' tumor 1 (WT1) (3).

The human WTI gene is located at chromosome locus 11 p13 comprising 10 exons. Alternative splicing occurs at exon 5 (plus or minus 17AA) and exon 9 (plus or minus KTS) in mRNA of WT1. These two alternative splicing sites yield four different isoforms: WT1+/+, WT1+/-, WT1-/+ and WT1-/- $(4,5)$. Loeb et al demonstrated that WT1 mRNA and protein was detected in nearly $90 \%$ of breast cancers but not in most normal breast samples (6). Moreover, Navakanit et al reported that the siRNA against WT1 inhibited both WT1 protein expression level and growth of breast cancer cell line MCF-7, in a dose- and time-dependent manner. These results suggested that WT1 may act as an oncogene in the breast cancer cell line MCF-7. Furthermore, WT1 may play a role in the pathogenesis of breast cancer as an oncogene rather than a tumor suppressor gene as in leukemia (7). Additionally, the high level expression of WT1 mRNA detected by realtime RT-PCR can predict a poor prognosis in breast cancer patients (8) and the absence of mutations through the whole 10 exons of the $W T 1$ gene in the 36 cases of primary breast cancer (9). WTI encodes a zinc finger acting as a transcriptional activator or repressor for many genes involved in cell differentiation, growth and apoptosis. These functions depend on the type of cells, WT1 isoforms and the status of targeted molecules. There are several targeted molecules for WT1 including growth factor genes: IGF-II, PDGF-A, CSF-1 and TGF- $\beta 1$, growth factor receptor genes: insulin receptor, IGF-1R and EGFR, and transcription factor and other genes, including: Egr1, PAX4, p53, c-myc, Bcl-2, cyclin E, Bak, Bax $(10,11)$. However, the relationship between WT1 and the targeted molecules involved in breast cancer remains unclear 
and the overview study of the relationship between WT1 and the related molecules has not been reported.

MDA-MB-468 breast cancer cells are estrogen receptor (ER), progesterone receptor (PR) and HER2-negative (12). The cells have a very high number of the epidermal growth factor receptors (EGFRs) which is growth inhibited by EGF and mediated apoptosis $(13,14)$. Moreover, the cells have a p53 mutation, $\mathrm{G} \rightarrow>$ A mutation in codon 273 of the p53 gene resulting in an Arg $\rightarrow$ His substitution (15).

In the present study, we used siRNA against WT1 mRNA to silence WT1 expression and the relationship between WT1 and related proteins in the breast cancer cell line MDA-MB468 was investigated by proteomics analysis. The proteins were further identified by LC-MS/MS and database searching. These studies may provide further evidence to understand the relationship between WT1 and the related molecules in breast cancer.

\section{Materials and methods}

Cell culture. The human breast cancer cell line MDA-MB-468 was purchased from American Type Culture Collection. MDA-MB-468 was cultured in DMEM (Gibco-BRL) supplemented with $10 \%$ fetal bovine serum, $100 \mathrm{U} / \mathrm{ml}$ of penicillin, and $100 \mu \mathrm{g} / \mathrm{ml}$ of streptomycin and $10 \%$ glutamine. Then, the cells were incubated in a $37^{\circ} \mathrm{C}$ incubator with $5 \% \mathrm{CO}_{2}(7)$.

Small interfering RNA (siRNA) transfection. MDA-MB-468 at $1 \times 10^{5}$ cells were seeded in each well of 24-well culture plates and incubated in a $\mathrm{CO}_{2}$ incubator at $37^{\circ} \mathrm{C}$ for $24 \mathrm{~h}$. The cells were transfected using Lipofectamine ${ }^{\circledR} 2000$ reagent (Invitrogen) in 24-well plates with $200 \mathrm{nM}$ siRNA duplexes (optimal siRNA conditions performed in preliminary study and data not shown). The siRNA against WT1 (siRNA $\left.{ }_{\mathrm{WT} 1}\right)$ (Invitrogen) consisted of a mixture of two 25-nt duplexes, i.e., siRNA WT1 $_{1}$ R8 (5'-AAATATCTCTTATTGCAGCCT GGGT-3') and siRNA ${ }_{\mathrm{WT1}}$ R90 (5'-TTTCACACCTGTATGTCT CCTTTGG-3'). To minimize the cytotoxicity of the reagent itself, the cells were washed once with PBS and the media was changed $6 \mathrm{~h}$ after transfection (7). After $72 \mathrm{~h}$, the cells were harvested and the protein level was investigated by western blot analysis.

Western blot analysis. Cell pellets were harvested by trypsinization and extracted with radioimmunoprecipitation assay (RIPA) buffer (Pierce, USA). Then, the concentration of protein was determined by the Bradford assay (Bio-Rad, Hercules, CA, USA). The $50 \mu \mathrm{g}$ of protein samples were loaded to $12 \%$ SDS-polyacrylamide gel electrophoresis and transferred to a nitrocellulose membrane (Bio-Rad). The membrane was blocked by blocking solution [5\% low fat dry milk in 1X TTBS (0.1\% Tween-20, $154 \mathrm{mM} \mathrm{NaCl}, 48 \mathrm{mM}$ Tris-base)] for $1 \mathrm{~h}$ and washed $5 \mathrm{~min}$ for three times with washing solution (1\% low fat dry milk in 1X TTBS buffer). After blocking, the blot was incubated with primary antibody anti-WT1 (1:200), anti-rhoGEF $(1: 1,000)$ and anti-actin $(1: 1,000)$ antibodies (diluted with $1 \%$ low fat dry milk in $1 \mathrm{X}$ TTBS) for $2 \mathrm{~h}$ and washed $5 \mathrm{~min}$ for three times with washing solution. The membrane was then incubated with secondary antibody polyclonal anti-IgG rabbit $(1: 10,000)$ antibody in $1 \%$ low fat dry milk in $1 \mathrm{X}$ TTBS for
$1 \mathrm{~h}$ and washed three times (10 $\mathrm{min} /$ wash). The proteins were visualized using a chemiluminescent detection kit (Pierce) and exposed to X-ray film (7).

\section{Proteomics analysis}

One-dimensional electrophoresis (1-DE). After transfection, siRNA ${ }_{\text {neg }}{ }^{-}$and siRNA WT1 $^{-}$transfected cell pellets from MDA-MB-468 were extracted with $0.5 \%$ SDS. Protein quantification was calculated using the Lowry method. Total protein samples of $50 \mu \mathrm{g}$ were loaded onto $12.5 \% \mathrm{SDS}$-polyacrylamide gel and a marker lane (low range marker; GE Healthcare) was added for calculation of the molecular weight of the protein bands. The gel was run at $20 \mathrm{~mA} / \mathrm{gel}$ for $1.45 \mathrm{~h}$. After electrophoresis, the gel was fixed in fixing solution (40\% ethanol, $10 \%$ acetic acid) and stained with Colloidal Coomassie Blue G-250 (8\% ammonium sulfate, $0.8 \%$ phosphoric acid, $0.08 \%$ Coomassie Brilliant Blue G-250 and 20\% methanol). Then, the gel was scanned with EPS 601 scanner (Bio-Rad) and the gel bands were fractionated to 15 slices and excised from the bottom to the top of the gel lane and each slice was cut into $1 \mathrm{~mm}$ cubes. The gel pieces were transferred into a well of low binding 96-well plates.

In-gel digestion. The gel pieces were destained by washing twice with $25 \mathrm{mM}$ ammonium bicarbonate in $50 \%$ methanol and further washed with $100 \%$ acetonitrile. Dried gel pieces were added with $20 \mu \mathrm{l}$ of $10 \mathrm{mM}$ DTT in $10 \mathrm{mM}$ ammonium bicarbonate and incubated at $56^{\circ} \mathrm{C}$ for $1 \mathrm{~h}$, followed by the addition of $100 \mathrm{mM}$ iodoacetamide in $10 \mathrm{mM}$ ammonium bicarbonate. The gel pieces were then digested with $10 \mu \mathrm{l}$ of $10 \mathrm{ng} / \mu \mathrm{l}$ sequencing grade modified porcine trypsin (Promega, USA) in $10 \mathrm{mM}$ ammonium bicarbonate solution and incubated at $37^{\circ} \mathrm{C}$ overnight. The peptides were extracted by addition of $30 \mu \mathrm{l}$ of $50 \%$ acetonitrile in $0.1 \%$ formic acid and dried at $40^{\circ} \mathrm{C}$ overnight.

LC-MS/MS and protein identification. The dried extracted peptides were resuspended with $12 \mu \mathrm{l}$ of $0.1 \%$ formic acid and transferred to low binding microcentrifuge tube. Solution was centrifuged at $10,000 \mathrm{rpm}$ for $10 \mathrm{~min}$ and transferred to vial tube. The resuspended peptide was injected to LC-MS/MS (ESI-QUAD-TOF mass spectrometry). The peptide sequences from LC-MS/MS were analyzed by Mascot Search and identified by NCBInr database.

\section{Results and Discussion}

siRNA against WT1 transfection in MDA-MB-468 cell line. The MDA-MB-468 breast cancer cell line was transfected with $200 \mathrm{nM}$ of siRNA against WT1 $\left(\mathrm{siRNA}_{\mathrm{WT1}}\right)$ compared to control ( $\mathrm{siRNA}_{\text {neg }}$ ) for $72 \mathrm{~h}$. After transfection of the cells we detected WT1 level by western blot analysis. The results showed that knockdown of WT1 led to decrease in WT1 protein expression in MDA-MB-468 (Fig. 1A).

$1-D E$. The quantitative proteomic, one-dimensional gel electrophoresis (1D-PAGE) was carried out to determine the protein expression patterns between siRNA ${ }_{\text {neg }}$ compared to siRNA $_{\mathrm{WT} 1}$ in MDA-MB-468. Fig. 1B1 represents the protein patterns obtained from 1D-PAGE. Lane 1 and 2 show the 


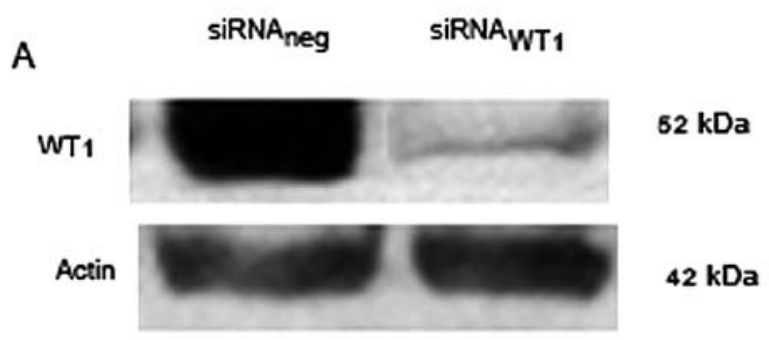

B1

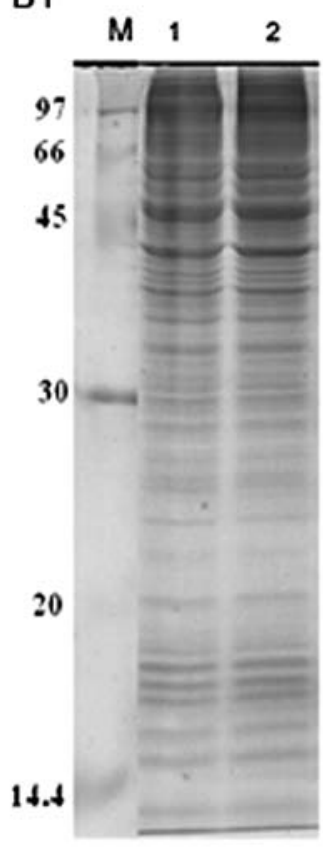

B2

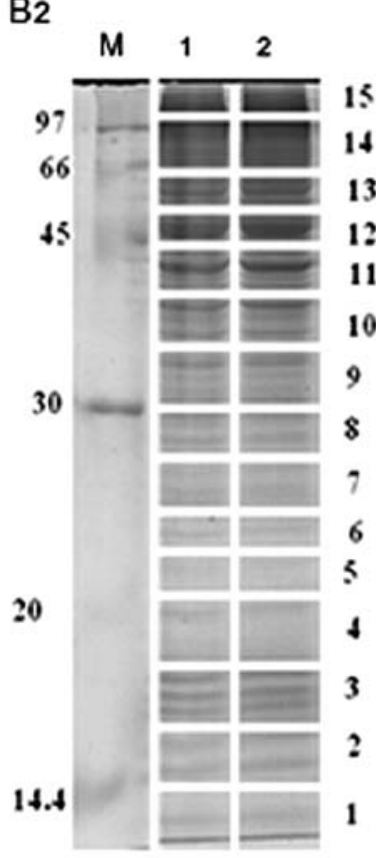

$$
\begin{aligned}
& M=\text { Marker } \\
& 1=\text { siRNA } \\
& 2=\text { siRNA }_{W T} 1
\end{aligned}
$$

Figure 1. (A) siRNA ${ }_{W T 1}$ transfection in the MDA-MB-468 cell line. MDA-MB-468 was transfected with $200 \mathrm{nM}$ of siRNA $\mathrm{WT}_{1}$ for $72 \mathrm{~h}$. Total protein $(50 \mu \mathrm{g})$ was detected by western blot analysis; (B) SDS-gel image $(12.5 \%)$ of protein pattern between siRNA ${ }_{\text {neg }}$ compared to siRNA ${ }_{\mathrm{WT1}}$ in MCF-7 and MDA-MB-468 $\left(\mathrm{B}_{1}\right)$ and gel after fractionation into 15 slices $\left(\mathrm{B}_{2}\right)$. siRNA, small interfering RNA; WT1, Wilms' tumor 1.

protein bands of siRNA ${ }_{\text {neg }}$ and siRNA ${ }_{\mathrm{WT} 1}$, respectively. After 1D-PAGE, the gels were cut into 15 slices as shown in Fig. $1 \mathrm{~B} 2$.

The quantification of protein from 1D-PAGE was analyzed by the DeCyder ${ }^{\mathrm{TM}}$ MS 2.0 Differential Analysis Software (GE Healthcare). The protein expressions of siRNA ${ }_{\mathrm{WT} 1}$ and siRNA were compared. The different intensity of protein expression in both conditions is shown in Venn's diagram (Fig. 2A). These demonstrated all possible relations of protein expressions in two conditions. The protein names and their biological functions of expressed proteins found only in siRNA $\mathrm{WT}_{\mathrm{W} 1}$ are listed in Table I and the expressed proteins found only in siRNA ${ }_{\text {neg }}$ are listed in Table II. Table III shows the protein names and the biological functions of expressed proteins found in siRNA $\mathrm{WT}_{\mathrm{WT1}}$ and siRNA ${ }_{\text {neg }}$. Rho guanine nucleotide exchange factor 1 (Rho-GEF) was selected to validate by western blot analysis. The result showed the presence of Rho-GEF only in WT1 presence in the cell (Fig. 2B).

Due to p53 mutation in MDA-MB-468 (15), the apoptosis pathway may occur via p53 independently. Notably, a novel target protein of WT1, mitogaligin, was found when WT1 was silenced. Mitogaligin is a 96 amino acid protein highly cationic and rich in tryptophan (16). This protein contains two localization signals, mitochondria and nucleus. Mitogaligin is mainly localized in mitochondria and promotes the release
A

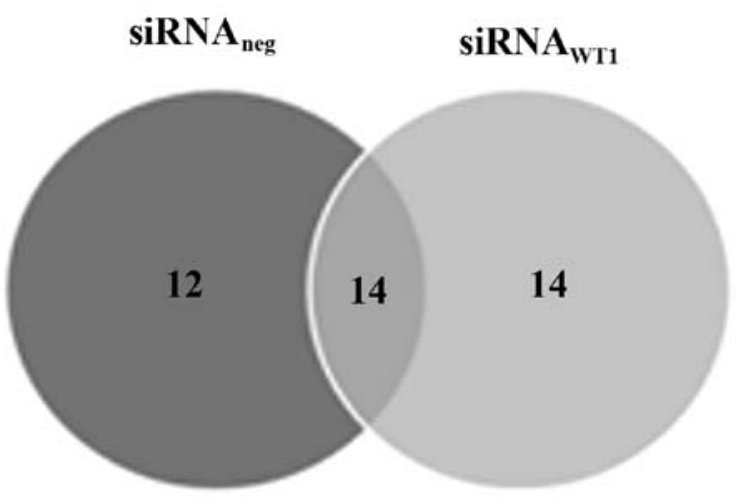

B

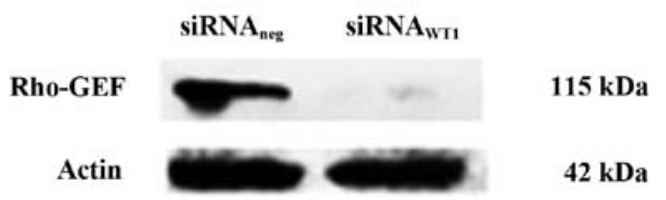

Figure 2. (A) Venn's diagram of protein expression with different intensity between siRNA WT1 $_{\text {transfection and siRNA }}$ control of MDA-MB-468; (B) Rho-GEF was validated by western blot analysis. siRNA, small interfering RNA; WT1, Wilms' tumor 1; Rho-GEF, Rho guanine nucleotide exchange factor 1 . 
Table I. Identification of expressed proteins found only in MDA-MB-468 siRNA ${ }_{\mathrm{WT} 1}$ using DeCyder $^{\mathrm{TM}}$ MS 2.0 Differential Analysis Software.

\begin{tabular}{|c|c|c|c|}
\hline Protein name & Accession no. & Peptide & $\begin{array}{l}\text { Mowse } \\
\text { score }\end{array}$ \\
\hline \multicolumn{4}{|l|}{ Apoptosis } \\
\hline Mitogaligin & gil12005991 & AWRMGEPACWGR & 9.50 \\
\hline \multicolumn{4}{|l|}{ Cell signaling } \\
\hline IBTK protein, partial & gil34192875 & SLDVLSDGVLK & 27.56 \\
\hline $\mathrm{SH} 2$ domain-containing protein $3 \mathrm{C}$ isoform a & gil41281821 & RSSASISR & 11.47 \\
\hline \multicolumn{4}{|l|}{ Structural protein } \\
\hline Cytokeratin 9 & gil435476 & GGSGGSYGGGGSGGGYGGGSGSR & 91.06 \\
\hline Keratin 10 & gil21961605 & SQYEQLAEQNRK & 50.17 \\
\hline Keratin, type II cytoskeletal 1 & gil119395750 & SLNNQFASFIDK & 98.71 \\
\hline Type I keratin $16^{\circ}$ & gil1195531 & APSTYGGGLSVSSR & 30.64 \\
\hline \multicolumn{4}{|l|}{ Protein folding } \\
\hline Ankyrin repeat domain-containing protein 62 & gil302393830 & LNDLNDRDK & 13.03 \\
\hline \multicolumn{4}{|l|}{ Gene regulation } \\
\hline SON DNA binding protein isoform $\mathrm{E}$ & gil17046381 & NRDKGEKEK & 10.73 \\
\hline \multicolumn{4}{|l|}{ Redox-regulation } \\
\hline Selenoprotein I & gil119621096 & KMAASTRVEASR & 5.30 \\
\hline \multicolumn{4}{|l|}{ Transport } \\
\hline $\begin{array}{l}\text { Synaptosomal-associated protein } 23 \text { isoform } \\
\text { SNAP23A }\end{array}$ & gil18765729 & KLIDS & 4.17 \\
\hline \multicolumn{4}{|l|}{ Unknown } \\
\hline hCG2042301 & gil119611404 & TGGDRTKAQRHEIISLS & 11.14 \\
\hline Unknown protein IT12 & gil2792366 & SGARAMAKAKK & 7.15 \\
\hline Unnamed protein product & gil21757251 & LINDSTNK & 19.40 \\
\hline
\end{tabular}

siRNA, small interfering RNA; WT1, Wilms' tumor 1.

of cytochrome $c$ resulting in the induction of cell death (17). Moreover, it can also be directed to the nucleus and can play a role in apoptotic properties leading to cell death (18). The STRING shows the correlation between WT1 and mitogaligin via EGFR (Fig. 3A). WT1 may act as negative regulator of mitogaligin through the EGFR leading cell death.

WT1 interacts with many genes involved in the cell signaling pathway. In the present study, the proteins involved in the cell signaling pathway, platelet-derived growth factor receptor $\alpha$ (PDGFRA) and Rho-GEF were found when WT1 was present in MDA-MB-468, while SH2 domain-containing protein and IBtK were found when the cell was without WT1. However, the STRING 9.05 showed that these molecules were not associated with WT1 (Fig. 3B).

The signal transduction pathway in the MDA-MB-468 breast cancer cell line was related to the mTOR signaling pathway that regulates cell growth, proliferation, differentiation and survival (19). The mTOR protein exists in two distinct complexes, mTOR complex 1 (mTORC1) and mTOR complex 2 (mTORC2). mTORC1 contains the protein raptor while mTORC 2 contains the protein rictor. In the presence of growth factors, activated Akt phosphorylates and inhibits tuberous sclerosis protein 2 (Tsc2), thereby promoting the activation of Rheb. Activated Rheb (Rheb-GTP) helps activate mTORC1, which in turn stimulates cell growth. Furthermore, mTORC2 phosphorylates Akt at Ser473 and regulates the actin cytoskeleton and cell motility (20). Recently, Razmara et al demonstrated that PDGFRs are essential for multiple growth factor signaling pathways that lead to PI3K/Akt activation. The pathway from PDGFR leads to phosphorylation of Akt which is involved in both the mTORC 2 and PLC $\gamma / \mathrm{PKC}$ pathways (21).

The WT1 protein has two nuclear localization domains: within zinc fingers I and within zinc fingers II and III. It is responsible for transcription and RNA processing (22). However, WT1 can be detected in the cytoplasm of various cell lines including breast cancer and shuttles the nucleus and the cytoplasm $(23,24)$. PDGFRA is a tyrosine-protein kinase that acts as a cell surface receptor for PDGFA and plays a role in the regulation of cell proliferation and survival (25). Rho-GEF is an intracellular signaling molecule that regulates cytoskeleton organization, gene expression, cell cycle progression, cell motility and other cellular processes. It represents the activating enzymes of Rho GTPases by serving to relay a variety of signals to catalyze GDP/GTP exchange of specific Rho GTPases (26). 
Table II. Identification of expressed proteins found only in MDA-MB-468 siRNA neg $_{\text {using DeCyder }}{ }^{\mathrm{TM}}$ MS 2.0 Differential Analysis Software.

Protein name

Cell adhesion

Vang-like protein 1 isoform 1

Rho guanine nucleotide exchange factor 11

isoform 1

Structural

\section{Keratin 5}

Peroxisome assembly protein 26 isoform a hHa7 protein

Transport

$\mathrm{Na}+\mathrm{K}+$-ATPase $\alpha 3$ subunit variant

Unknown function

Unnamed protein product

hCG2042050

Chromosome 9 open reading frame 39

Hypothetical protein LOC286076 gil20373171

HMAGLK

gil30047763

VFEPVPEGDGHWQGR

gil39645305

gil7662086

VPSIKLVYTLTVPEATVK

SSNSK

11.73

gil18999435
gil 8923625
gil50949256

Peptide

Mowse

score

LAELEEALQK

KSDSSTSAAPLR

NTLNGHEK

gil62898870

LNIPVSQVNPR

14.46

gil194390014

MFHLAAFKLK

22.44

gil119579649

ASTVPDLK

7.42

gil119579068

LLEGQSLALSPR

11.96

gil119602615

DVGDALPR

29.47

siRNA, small interfering RNA; WT1, Wilms' tumor 1. PDGFRA, platelet-derived growth factor receptor $\alpha$.

A

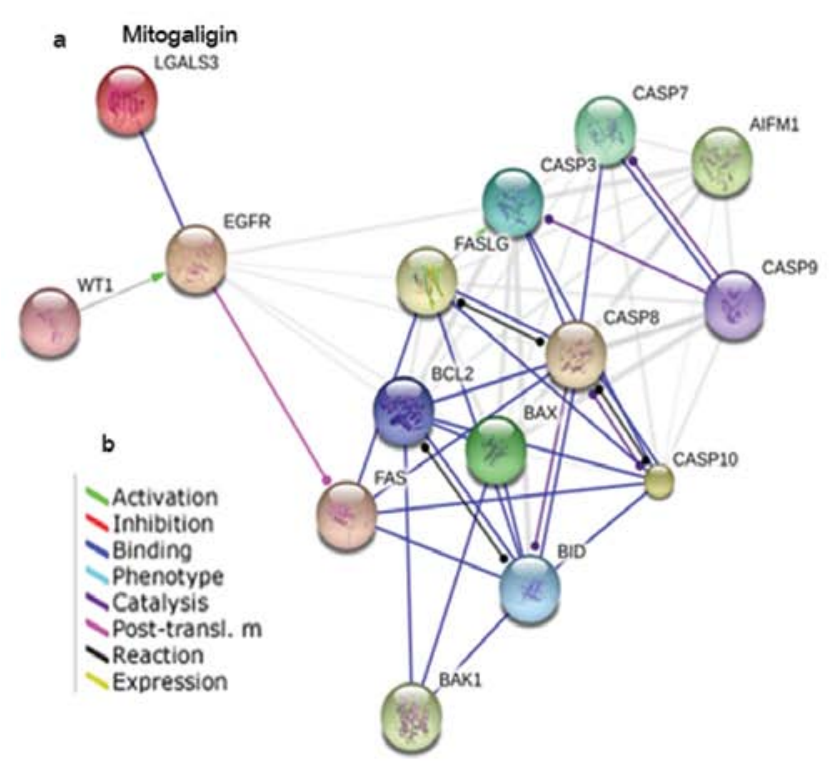

B

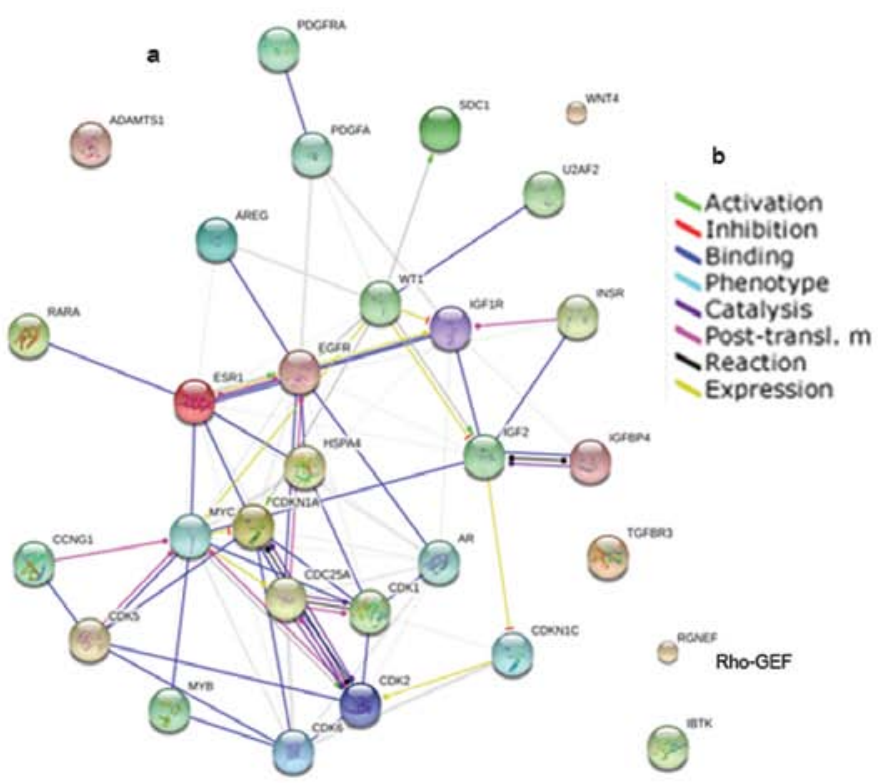

Figure 3. (A-a) The involvement of WT1 and p53-independent apoptosis pathway in MDA-MB-468 (STRING 9.05). (b) Modes of action are shown in different colors. The red circle shows the proteins found in this study. (B-a) The involvement of WT1 and proteins in signal transduction pathway in MDA-MB-468 (STRING 9.05). (b) Modes of action are shown in different colors. The red circle shows the proteins found in this study. WT1, Wilms' tumor 1; BAK1, Bcl-2 homologous antagonist killer; BID, BH3 interacting domain death agonist; FASLG, Fas ligand; BCL-2, B-cell lymphoma-2; BAX, Bcl-2-associated X protein; LGALS3, mitogaligin; EGFR, epidermal growth factor receptor; PDGFRA, platelet-derived growth factor receptor $\alpha$; RARA, retinoic acid receptor $\alpha$; IBtK, inhibitor of Bruton's tyrosine kinase. 
Table III. Identification of expressed proteins found in MDA-MB-468 siRNA WT1 $_{1}$ and MDA-MB-468 siRNA neg $_{\text {using DeCyder }}{ }^{\mathrm{TM}}$ MS 2.0 Differential Analysis Software.

Protein name

Structural protein

LMNA protein

Cell differentiation and survival

Nance-Horan syndrome protein isoform 2

Sestrin-2

Cell signaling

S100 calcium binding protein A10 [Annexin II ligand,

calpactin I, light polypeptide (p11)], isoform CRA_b

Chain A, catalytic domain of human phosphodiesterase $4 \mathrm{~b}$

in complex with piclamilast

Protein S100-A6

Hormone

C-type natriuretic peptide precursor

Protein folding

Heat shock protein

Transport

Ras association domain-containing protein 9

Gene regulation

TTLL5 protein

39S ribosomal protein L15, mitochondrial

Unknown function

hCG16415, isoform CRA_f

FLJ00258 protein

Pyruvate dehydrogenase E1 $\alpha$ subunit
Accession no.

Peptide

Mowse score

\begin{tabular}{llr} 
gil21619981 & SGAQASSTPLSPTR & 44.82 \\
gil42384238 & KTISGIPR & 26.98 \\
gil13899299 & KLSEINK & 21.68 \\
gil119573783 & NALSGAGEASAR & 11.49 \\
gil58177395 & GMEISPMXDK & 8.66 \\
& & \\
gil7657532 & LQDAEIAR & 43.91 \\
gil13249346 & YKGANKKGLSK & 10.08 \\
gil4204880 & IINEPTAAAIAYGLDKK & 27.1 \\
& & \\
gil114155158 & ADAFLPVPLWR & 6.35 \\
gil33877151 & MGNTMDKR & 10.31 \\
gil7661806 & CGRGHK & 16.37 \\
gil119611935 & GAECCPGGPVK & 10.83 \\
gil18676718 & GSMSR & 8.83 \\
gil861534 & EEIPPHSYR & 6.28 \\
\hline
\end{tabular}

siRNA, small interfering RNA; WT1, Wilms' tumor 1.

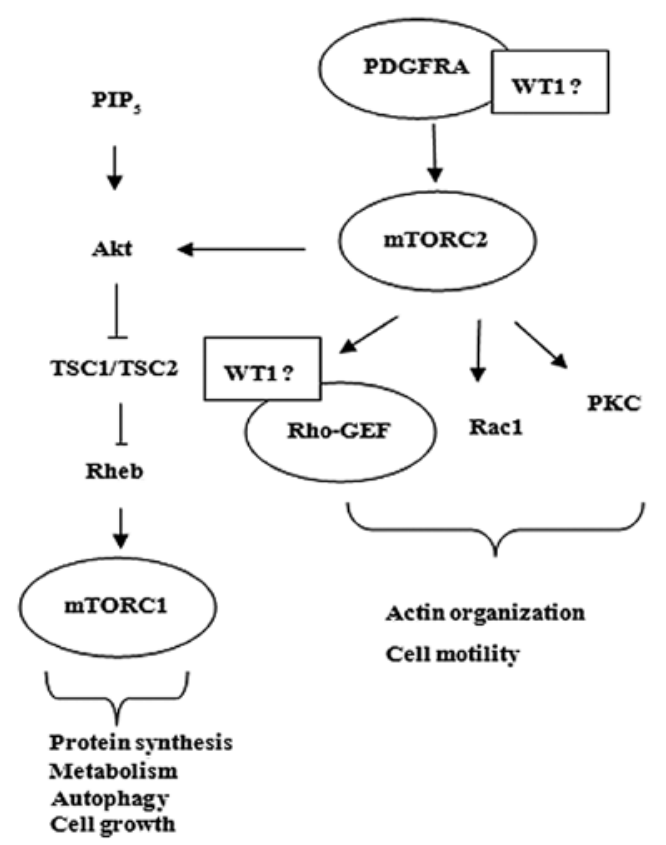

Figure 4. The possible relationship between WT1 and PDGFRA, Rho-GEF in signal transduction pathway in MDA-MB-468 [adapted from Zhou and Huang (20)]. WT1, Wilms' tumor 1; PDGFRA, platelet-derived growth factor receptor $\alpha$; Rho-GEF, Rho guanine nucleotide exchange factor 1 .
WT1 may be related to PDGFRA leading to activation of Akt/TSC1, TSC2/mTOR2 pathway resulting in cell growth. Moreover, WT1 may also be associated with mTOR2/ Rho-GEF resulting in cell motility (Fig. 4). Moreover, when WT1 was silenced with siRNA ${ }_{\text {WT1 }}$, IBtK, SH2 domain-containing protein were upregulated. The relationship between WT1 and these proteins in the signaling pathway in MDA-MB-468 has not previously been elucidated. WT1 may behave as a negative-regulator of IBtK that binds to $\mathrm{SH} 2$ domain of BtK tyrosine kinase receptor resulting in IBtK inactivate leading to B-cell differentiation (27).

\section{References}

1. Jemal A, Bray F, Center MM, Ferlay J, Ward E and Forman D: Global cancer statistics. CA Cancer J Clin 61: 69-90, 2011.

2. Adami HO, Signorello LB and Trichopoulos D: Towards an understanding of breast cancer etiology. Semin Cancer Biol 8: 255-262, 1998 .

3. Dumitrescu R and Cotarla I: Understanding breast cancer risk where do we stand in 2005? J Cell Mol Med 9: 208-221, 2005.

4. Gessler M, Poustka A, Cavenee W, Neve RL, Orkin SH and Bruns GA: Homozygous deletion in Wilms tumours of a zincfinger gene identified by chromosome jumping. Nature 343: 774-778, 1990.
Thus, WT1 plays an oncogenic role in MDA-MB-468. 
5. Haber DA, Park S, Maheswaran S, et al: WT1-mediated growth suppression of Wilms tumor cells expressing a WT1 splicing variant. Science 262: 2057-2059, 1993.

6. Loeb DM, Evron E, Patel CB, et al: Wilms' tumor suppressor gene $(W T 1)$ is expressed in primary breast tumor despite tumorspecific promoter methylation. Cancer Res 61: 921-925, 2001.

7. Navakanit R, Graidist P, Leeanansaksiri W and Dechsukum C: Growth inhibition of breast cancer cell line MCF-7 by siRNA silencing of Wilm tumor 1 gene. J Med Assoc Thai 90: 2416-2421, 2007.

8. Miyoshi Y, Ando A, Egawa C, et al: High expression of Wilms' tumor suppressor gene predicts poor prognosis in breast cancer patients. Clin Cancer Res 8: 1167-1171, 2002.

9. Oji Y, Miyoshi Y, Kiyotoh E, et al: Absence of mutations in the Wilms' tumor gene WT1 in primary breast cancer. Jpn J Clin Oncol 34: 74-77, 2004.

10. Yang L, Han Y, Saurez Saiz F and Minden M: A tumor suppressor and oncogene: the WT1 story. Leukemia 21: 868-876, 2007.

11. Graidist P: The role of WT1 in breast and other cancers: oncogene or tumor suppressor gene? Songkla Med J 27: 435-449, 2009

12. Subik K, Lee JF, Baxter L, et al: The expression patterns of ER, PR, HER2, CK5/6, EGFR, Ki-67 and AR by immunohistochemical analysis in breast cancer cell lines. Breast Cancer 4 $35-41,2010$.

13. Filmus J, Pollak MN, Cailleau R and Buick RN: MDA-468, a human breast cancer cell line with a high number of epidermal growth factor (EGF) receptors, has an amplified EGF receptor gene and is growth inhibited by EGF. Biochem Biophys Res Commun 128: 898-905, 1985.

14. Armstrong DK, Kaufmann SH, Ottaviano YL, Furuya Y, Buckley JA, Isaacs JT and Davidson NE: Epidermal growth factor-mediated apoptosis of MDA-MB-468 human breast cancer cells. Cancer Res 54: 5280-5283, 1994.

15. Holiday LD and Speirs V: Choosing the right cell line for breast cancer research. Breast Cancer Res 13: 215, 2011.

16. Guittaut M, Charpentier S, Normand M, Dubois J, Raimond J and Legrand A: Identification of an internal gene to the human Galectin-3 gene with two different overlapping reading frames that do not encode Galectin-3. J Biol Chem 276: 2652-2657, 2001.

17. Duneau M, Boyer-Guittaut P, Gonzalez P, et al: Galig, a novel cell death gene that encodes a mitochondrial protein promoting cytochrome $c$ release. Exp Cell Res 302: 194-205, 2005.
18. Robinet O, Mollet L, Gonzalez P, Normand T, Charpentier S, Brulé $\mathrm{F}$, et al: The mitogaligin protein is addressed to the nucleus via a non-classical localization signal. Biochem Biophys Res Commun 392: 53-57, 2010.

19. Yu K, Toral-Barza L, Discafani C, Zhang WG, Skotnicki J, Frost $\mathrm{P}$ and Gibbons JJ: mTOR, a novel target in breast cancer: the effect of CCI-779, an mTOR inhibitor, in preclinical models of breast cancer. Endocr Relat Cancer 8: 249-258, 2001.

20. Zhou $\mathrm{H}$ and Huang S: mTOR signaling in cancer cell motility and tumor metastasis. Crit Rev Eukaryot Gene Expr 20: 1-16, 2010.

21. Razmara M, Heldin CH and Lennartsson J: Platelet-derived growth factor-induced Akt phosphorylation requires mTOR/Rictor and phospholipase C- $\gamma 1$, whereas S6 phosphorylation depends on mTOR/Raptor and phospholipase D. Cell Commun Signal 11: 3, 2013.

22. Bruening W, Moffett P, Chia S, Heinrich G and Pelletier J: Identification of nuclear localization signals within the zinc fingers of the WT1 tumor suppressor gene product. FEBS Lett 393: 41-47, 1996.

23. Silberstein GB, Van Horn K, Strickland P, Roberts CT Jr and Daniel CW: Altered expression of WT1 Wilms tumor suppressor gene in human breast cancer. Proc Natl Acad Sci USA 94: 8132-8137, 1997.

24. Niksic M, Slight J, Sanford JR, Caceres FJ and Hastie ND: The Wilms' tumor protein (WT1) shuttles between nucleus and cytoplasm and is present in functional polysomes. Hum Mol Genet 13: 464-471, 2004.

25. Alberts B, Johnson A, Lewis J, Raff M, Roberts K and Walter P: Molecular Biology of the Cell. 5th edition. Garland Science, New York, 2008.

26. Shang X, Marchioni F, Evelyn CR, et al: Small-molecule inhibitors targeting G-protein-coupled Rho guanine nucleotide exchange factors. Proc Natl Acad Sci USA 110: 3155-3160, 2013.

27. Janda E, Palmieri C, Pisano A, Pontoriero M, Laccino E, Falcone $\mathrm{C}$, et al: Btk regulation in human and mouse $\mathrm{B}$ cells via protein kinase $\mathrm{C}$ phosphorylation of IBtk $\gamma$. Blood 117: 6520-6531, 2011. 